\title{
Pocket parks for promoting social interaction among residents of Baghdad city
}

\begin{abstract}
Purpose: The residents of Baghdad city has been suffering from various issues, including poor social relations, low quality of life, as well as neglect of many public spaces and small parks. Therefore, there is a need to devise effective alternatives to compensate for the loss of large public open spaces so as to enhance the residents' social interactions and other social activities. Having that said, this study identified the types and characteristics of public open spaces to enhance residents' social activities in Baghdad city. Design/methodology/approach: This study adopted the questionnaire survey method to gather quantitative data from 306 respondents based on the single-stage random procedure. The targeted population of this study refers to the residents of the Karkh district, the western part of Baghdad. Findings: The study outcomes highlight the need to provide pocket parks with adequate characteristics to promote the residents' social interactions in Baghdad city. Practical implications: This study contributes by emphasizing the significance of establishing pocket parks for social interaction in Baghdad City. Originality/value: The study shows a number of solutions related to pocket parks by studying the critical actionable attributes that can be embedded into new development, landuse policies, or to upgrade existing parks. The study may serve as a useful reference for urban and landscape planners, architects, social psychologists, the Municipal of Baghdad, and other interested researchers in this field.
\end{abstract}

Keyword: Social interaction; Well-being; Pocket parks; Small-nearby open spaces; Small parks characteristics; Landscape architecture 